\title{
Occurrence, histopathology and experimental transmission of hepatopancreatic parvovirus infection in Penaeus monodon postlarvae
}

\author{
E. S. Catap ${ }^{1, *}$, C. R. Lavilla-Pitogo ${ }^{1}$, Y. Maeno ${ }^{1,2}$, R. D. Traviña ${ }^{1}$ \\ ${ }^{1}$ Fish Health Section, SEAFDEC Aquaculture Department, Tigbauan, 5021, Iloilo, Philippines \\ ${ }^{2}$ Seikai National Fisheries Research Institute, Fisheries Research Agency, Taira 1551-8, Nagasaki 851-2213, Japan
}

\begin{abstract}
Hepatopancreatic parvovirus (HPV) was detected in samples of Penaeus monodon postlarvae (PL-13, PL-18, PL-19, PL-26) from 2 hatcheries in 2 provinces (Samar and Iloilo) in the Philippines. The percentage of infection was 20 to $100 \%$ in postlarvae obtained from the hatchery in Samar in August 2001. Postlarvae from the hatchery in Iloilo, sampled in October and November 2001, had 70 to $99 \%$ HPV infection. Wet mounts of squashed hepatopancreatic tissue stained with malachite green (wet-mount technique) and histopathology revealed the presence of large, usually single, basophilic intranuclear inclusion bodies in the distal tubules, which led to displacement of the nucleoli. Light microscopy showed ovoid to spherical inclusion bodies, 5 to $11 \mu \mathrm{m}$ in diameter. Transmission electron microscopy revealed that the inclusion bodies were composed of electron-dense granular material and virions. The virions appeared roughly spherical and averaged 18 to $22 \mathrm{~nm}$ in diameter. An experiment was undertaken to induce HPV infection by feeding $P$. monodon postlarvae with virus-infected postlarvae. P. monodon postlarvae (PL-16), initially determined as free from HPV, were found HPV-positive $24 \mathrm{~h}$ after being fed with infected material. The percentage of infection ranged from $30 \%$ at Day 1 post-infection (p.i.) to $100 \%$ at Day 7 p.i. determined by the wet-mount technique and by histopathology. This is the first report of a successful horizontal transmission of HPV in P. monodon postlarvae.
\end{abstract}

KEY WORDS: Hepatopancreatic parvovirus $\cdot$ HPV $\cdot$ Penaeus monodon $\cdot$ Postlarvae $\cdot$ Experimental infection $\cdot$ Histopathology $\cdot$ Wet-mount technique $\cdot$ Horizontal transmission

\section{INTRODUCTION}

Hepatopancreatic parvovirus (HPV) infection was first reported in samples of penaeid shrimp species obtained from China, Kuwait, Singapore and the Philippines (Lightner \& Redman 1985). Infected shrimp exhibit gross signs, such as anorexia and stunting, which are not specific to HPV. However, Flegel et al. (1999) reported that the degree of HPV infection was significantly related to the stunting of cultured Penaeus monodon in Thailand. In addition to poor growth, it could cause significant mortality in juvenile stages, particularly in cases of multiple-agent infections (Lightner et al. 1992).
Diagnosis of HPV is primarily based on the histopathology of affected cells of the hepatopancreas, typically characterized by the presence of single, large basophilic intranuclear inclusion bodies in their hypertrophied nuclei. Rapidly dividing E-cells (embryonic cells) at the distal end of the tubules are predominantly infected (Lightner 1996). A rapid diagnostic technique that can be employed in the field using Giemsastained impression smears of hepatopancreas has also been developed (Lightner et al. 1993). At present, the availability of a DNA probe and PCR primers (DiagXotics) for HPV isolated from Penaeus chinensis (HPV chin, from Korea) allows the rapid and nondestructive detection of low-grade HPV infections 
(Mari et al. 1995, Pantoja \& Lightner 2000). However, Phromjai et al. (2001) suggested that HPVchin and HPVmon (isolated from P. monodon cultured in Thailand) could be different varieties, based on the in situ hybridization results, their genome sizes and the sequence homology of PCR products. Consequently, there is a need to fully characterize HPV in other countries in which it occurs.

Since the initial report of Lightner \& Redman (1985), very limited studies about HPV have been undertaken in the Philippines (Gomez 1998). Although there are some hypotheses regarding the mode of HPV transmission, there are no published reports on the experimental induction of HPV infection (Lightner et al. 1992) in any penaeid shrimp species; thus, this aspect remains to be fully elucidated. We report here the occurrence of HPV infection and describe its pathology in Penaeus monodon postlarvae (PL) obtained from 2 private hatcheries in the Philippines. We also describe the successful experimental infection of HPV in $P$. monodon PL.

\section{MATERIALS AND METHODS}

Occurrence of HPV. Samples from a hatchery on the island of Samar, eastern Philippines, were obtained in August 2001, and 3 separate batches of PL were sampled from a hatchery in Iloilo, in the western Philippines, from October to November 2001 (see Table 1 for total number of samples obtained for each batch of PL and number of samples examined with wet-mount technique and histopathology). The samples were initially examined by means of wet mounts of squashed hepatopancreatic tissue stained with $0.05 \%$ malachite green (wet-mount technique). Subsequent examination using histopathology of hematoxylin-eosin-stained sections was used for confirmation. Some samples were also fixed for transmission electron microscopy.

Histopathology of HPV infection in Penaeus monodon. Samples (PL-13) from the hatchery on Samar Island were fixed for light and electron microscopy observations following the procedure described by Bell \& Lightner (1988). Briefly, for light microscopy, postlarvae were fixed whole in Davidson's fixative overnight, then transferred to $70 \%$ ethanol and passed through a dehydrating series of ethanol. Tissues were embedded in paraffin wax, sectioned at $5 \mu \mathrm{m}$, and stained with hematoxylin and eosin (H\&E).

For transmission electron microscopy, cephalothorax portions of postlarvae were fixed for $3 \mathrm{~h}$ in a mixture of $2.5 \%$ glutaraldehyde-2\% paraformaldehyde ( $\mathrm{pH} 7.4$ ) in $0.2 \mathrm{M}$ cacodylate buffer solution. After fixation, tissues were rinsed 3 times with ice-cold cacodylate buffer solution and post-fixed with $1 \%$ osmium tetroxide for $2 \mathrm{~h}$ at $4^{\circ} \mathrm{C}$. The specimens were then dehydrated at $4{ }^{\circ} \mathrm{C}$ in a graded series of ethanol (10 min each in 30, 50, 70, 90 and $95 \%$ and twice in absolute ethanol) and subsequently embedded in Quetol 812 (Nissin EM). Ultrathin sections were stained with $1 \%$ uranyl acetate and $1 \%$ lead citrate, and then examined with a JEOL-100S transmission electron microscope.

Experimental transmission of HPV. Postlarvae (2000 samples, PL-16) were purchased from a private hatchery in Tigbauan, Iloilo, Philippines, and placed in a circular fiberglass tank (200 l capacity) with aerated seawater. After $4 \mathrm{~d}$ in the holding tank, where they were fed once daily with $200 \mathrm{ml}$ Artemia sp. nauplii (50 nauplii $\mathrm{ml}^{-1}$ ), the PL were randomly distributed in $5 \times 10 \mathrm{l}$ glass tanks (300 PL tank ${ }^{-1}$ ) filled with $5 \mathrm{l}$ of UV-sterilized and well-aerated seawater. Prior to distribution in glass tanks, 20 postlarval samples were examined for the presence of HPV inclusion bodies using the wet-mount technique. No HPV infection was detected.

Postlarvae from the hatchery in Iloilo, which histological examination (PL-26 stored at $-80^{\circ} \mathrm{C}$ ) had revealed to be infected with $\mathrm{HPV}$, were fed to the experimental postlarvae $3 \mathrm{~d}$ after transfer to the glass tanks. We added $2.0 \mathrm{~g}$ of frozen PL once to each of the 4 HPV-treated tanks. To serve as control, the PL in 1 tank were fed with Artemia sp. instead of with HPVinfected material. After $24 \mathrm{~h}$, half of the water in each tank was replaced with UV-sterilized seawater. Examination of the postlarvae by the wet-mount technique (5 PL from each of the 5 tanks) and histopathology (10 PL from each 5 tanks) was undertaken on Days 1, 3, 5 and 7 post-infection (p.i.; after feeding with infected PL). During the experimental period, the PL in each tank were fed daily with $10 \mathrm{ml}$ Artemia sp. nauplii (50 nauplii $\mathrm{ml}^{-1}$ ), except on the day preceding and during the infection treatment. Temperature during the experiment ranged from 25 to $30^{\circ} \mathrm{C}$; one-half to twothirds of the water in each tank was replaced daily with UV-sterilized seawater.

\section{RESULTS AND DISCUSSION}

\section{Occurrence and pathology of HPV}

Table 1 presents the data on HPV-infected postlarvae from the 2 hatcheries in the Philippines. The samples from Samar were all PL-13 while those from Iloilo were PL-18, PL-19 and PL-26. No other pathogen was detected in these samples. Inadvertent detection of HPV usually occurs when, as part of shrimp health monitoring and husbandry practices, PL are submitted to diagnostic laboratories and examined for the pres- 
ence of any pathogen prior to pond culture (Platon 1999). Although Lightner \& Redman (1985) associated poor survival with HPV infection in juveniles of presumed Penaeus monodon samples from the Philippines, the prevalence of HPV was quite low compared to that of infectious hypodermal and hematopoietic necrosis virus (IHHNV) and monodon baculovirus (MBV) infections, and thus was considered of minor importance. It is likely that HPV infection is only easily detectable in older PL (unlike MBV, which can be identified as early as Zoea 3 stage: Fegan et al. 1991); thus, HPV could be easily overlooked and remain undetected. Moreover, since there is very little published work on HPV, it is not as well known as MBV or white spot syndrome virus (WSSV). In fact, the technician at the Iloilo hatchery from which we obtained our samples had not even heard about HPV until informed about the infected PL. Thus, in terms of viruses, most hatchery owners and shrimp farmers are more concerned with MBV and/or WSSV.

Based on recorded cases at the Fish Health Section of SEAFDEC, the annual prevalence of HPV infection in Iloilo from 1993 to 1996 ranged from 1.5 to $9.4 \%$ among hatchery-reared PL (Gomez 1998). In the present study, the prevalence of HPV, based on histopathology, ranged from 20 to $100 \%$ and 70 to $99 \%$ of the PL sub-sampled from the total samples obtained from Samar and Iloilo, respectively (Table 1). The economic impact of high HPV infection, such as that recorded in our samples, has not been established. It was initially suggested that the percentage of HPVinfected larvae prior to pond stocking would approximately correspond to the expected minimum mortality for that pond based on the experiences of Thai shrimp farmers (Sukhumsirichart et al. 1999). This means that an infection rate of $60 \% \mathrm{HPV}$ in PL prior to stocking would result in roughly $60 \%$ mortality in culture ponds. However, it now appears that infected shrimp do not actually die, but grow very slowly, and thus may

Table 1. Penaeus monodon. Hepatopancreatic parvovirus (HPV)-infected postlarvae (PL) samples from 2 private hatcheries in Philippines. All samples were obtained in year 2001. Total no. samples: total number PL from 3 different tanks (50 PL tank ${ }^{-1}$ ) in same hatchery. N: number of samples examined; uib: unidentified inclusion bodies

\begin{tabular}{|lcccccc|}
\hline $\begin{array}{l}\text { Hatchery } \\
\text { sample date }\end{array}$ & $\begin{array}{c}\text { Total no. } \\
\text { samples }\end{array}$ & $\begin{array}{c}\text { Stage } \\
\text { examined }\end{array}$ & $\begin{array}{c}\text { Wet mount } \\
\text { N } \% \text { HPV-positive }\end{array}$ & $\begin{array}{c}\text { Histopathology } \\
\text { N } \% \text { HPV-positive }\end{array}$ \\
\hline $\begin{array}{l}\text { Samar } \\
\text { August }\end{array}$ & 150 & PL-13 & 10 & 0 & 5 & $80(4 / 5)$ \\
& & & 10 & uib & 5 & $100(5 / 5)$ \\
& & & 10 & 0 & 5 & $20(1 / 5)$ \\
Iloilo & & & & & & \\
19 Oct & 3000 & PL-18 & 10 & $90(9 / 10)$ & 119 & $89(106 / 119)$ \\
23 Oct & 7000 & PL-26 & 20 & $95(19 / 20)$ & 93 & $99(92 / 93)$ \\
5 Nov & 10000 & PL-19 & 31 & $55(17 / 31)$ & 63 & $70(44 / 63)$ \\
\hline
\end{tabular}

not be sampled by the nets. Harvest losses incurred from stunted shrimp can sometimes be considerable, since stunted shrimp are much less valuable than normal shrimp. Therefore, it is necessary to check also for HPV in PL prior to pond-stocking (Flegel et al. 1999).

No external or gross signs associated with HPV were observed in the samples. The wet-mount technique showed single inclusion bodies that presumably indicated HPV infection. This is the first report on the detection of HPV using this wet-mount technique. Table 1 shows that the percentages of HPV-positive samples based on the wet-mount technique and histopathology are comparable, except for the samples from the Samar hatchery. Some problems in the identification of the single inclusion bodies were encountered when the PL from Samar were screened using the wet-mount technique: no inclusion bodies were observed in the PL taken from 2 of 3 tanks (Table 1), with single inclusion bodies observed only in the PL from the other tank. However, these latter cases were not recorded and identified as HPV-infected PL. Therefore, histopathological examination of all 3 Samar tanks had to be undertaken. Thus, the wetmount technique is suitable for screening PL for MBV and HPV prior to pond stocking, but verification through histopathology should also be done, especially for early larval or PL stages, in which infection could be possibly overlooked by the less sensitive wet-mount detection method.

Histopathological examination of PL in the same batch confirmed the presence of basophilic intranuclear inclusion bodies (Fig. 1) typical of HPV infection. The developing inclusion bodies in the nuclei of the epithelial cells of the distal tubules of the hepatopancreas led to the displacement of the nucleoli. Necrosis or haemocytic infiltration of the hepatopancreas of infected postlarvae was not observed. While HPV is known to produce a single basophilic inclusion body in hypertrophied nuclei, some cells in the distal tubules in our samples exhibited 2 inclusions. It is likely that this is similar to the situation described by Sukhumsirichart et al. (1999) for HPV-infected Penaeus monodon in Thailand. Based on their transmission electron microscope (TEM) study, these authors proved that the 2 inclusion bodies were actually composed of viral arrays sectioned at different angles.

TEM of HPV-infected hepatopancreatocytes showed the inclusion body to be centrally located in the karyoplasm (Fig. 2). The developing inclusion bodies appeared ovoid to spherical in shape, with a diameter from 5 to 


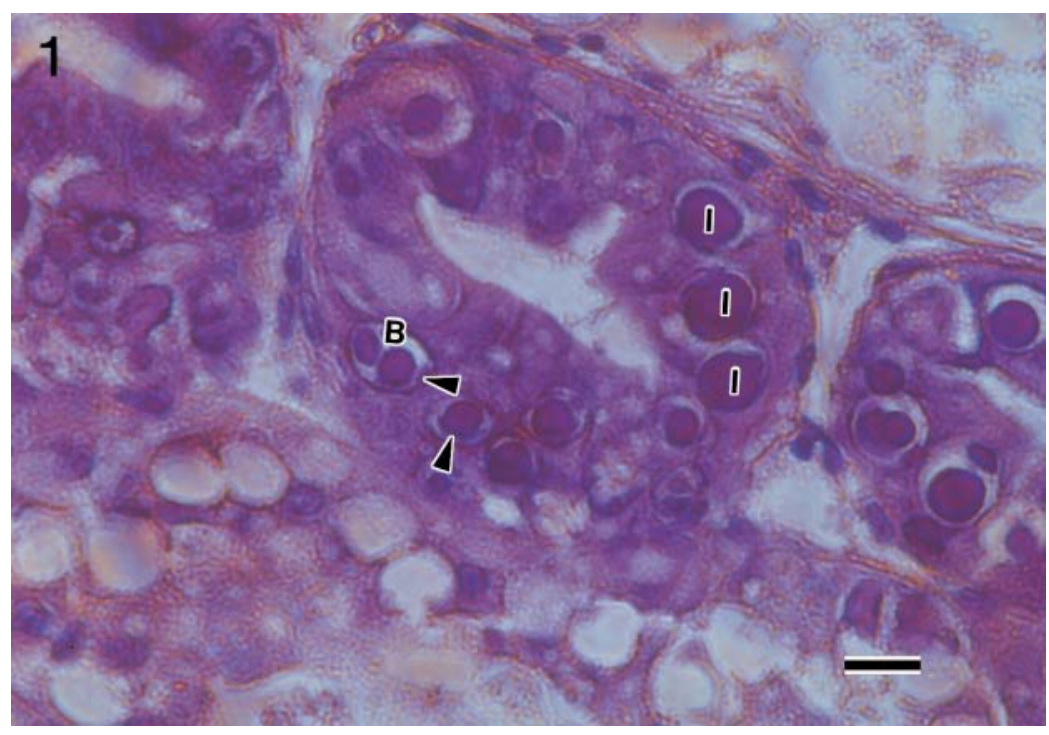

Fig. 1. Penaeus monodon. Hepatopancreatic parvovirus (HPV)-infected distal hepatopancreatic tubules of postlarvae showing hypertrophied nuclei with inclusion bodies (I) ranging from 5 to $11 \mu \mathrm{m}$. Basophilic nucleolis (arrowheads) are being compressed by growing inclusion bodies during early stage of development, while some hepatopancreatocytes exhibit 2 inclusion bodies (B). H\&E stain; scale bar $=10 \mu \mathrm{m}$

$11 \mu \mathrm{m}$, and were composed of fine, electron-dense granular material and virions. The inclusion bodies caused the lateral displacement of the nucleoli and margination of the chromatin. The virions, which are embedded in the virogenic stroma, appeared roughly spherical and averaged approximately 18 to $22 \mathrm{~nm}$ in diameter (Fig. 3). The size of the virions described here are within the range reported for different species of penaied shrimps (22 to $24 \mathrm{~nm}$ : Lightner \& Redman 1985, 21 to $22 \mathrm{~nm}$ : Roubal et al. 1989, 17 to $20 \mathrm{~nm}$ : Spann et al. 1997). Although the morphology of the virions and pathology of HPV in Penaeus monodon from the Philippines are now known, further molecular characterization of the virus is required to compare this with the HPVchin from Korea and HPVmon from Thailand. This information could be used to identify or improve detection methods appropriate for HPV in the Philippines.

\section{Experimental transmission of HPV in Penaeus monodon postlarvae}

Viral infection was already detectable $24 \mathrm{~h}$ after the experimental PL were fed with dead HPV-infected PL. Table 2 shows the percentage of HPV infection in samples based on the wet-mount technique and histopathological examination. The wet-mount technique was used as a preliminary procedure to detect the round HPV inclusion bodies (Fig. 4). The detection of HPV in postlarvae $24 \mathrm{~h}$ p.i. is similar to results previously reported for MBV, Baculovirus penaei (BP) and WSSV. However, a prevalence of $100 \%$ was obtained within $24 \mathrm{~h}$ p.i. for MBV and 48 to $72 \mathrm{~h}$ p.i. for BP (Natividad \& Lightner 1992, Hammer et al. 1998, Soto et al. 2001). These discrepancies could be attributable to the differences in the biology of the virus species involved, including the incubation periods and specificity of infection sites. HPV initially infects the generative E-cells of the distal tubules of the hepatopancreas. In contrast, MBV can infect all the cells of the hepatopancreas and anterior midgut, thus probably enabling it to establish infection more rapidly. The discrepancies could also be due to the different detection techniques and the methods of infection used in the respective experiments.

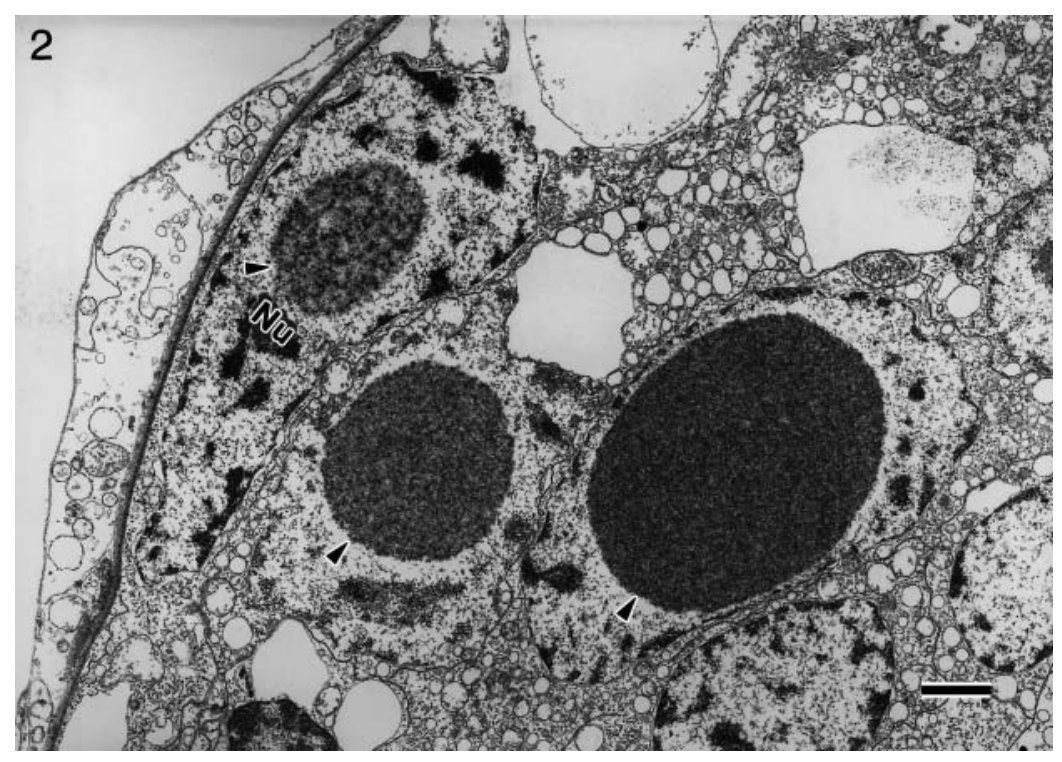

Fig. 2. Penaeus monodon. Electron-micrograph of HPV-infected hepatopancreatocytes. Mass of electron-dense virogenic stroma (arrowheads) is located centrally in karyoplasm of the hypertrophied nucleus; margination of chromatin and compression of nucleoli $(\mathrm{Nu})$ are evident. Uranyl acetate and lead citrate stain; scale bar $=2 \mu \mathrm{m}$ 


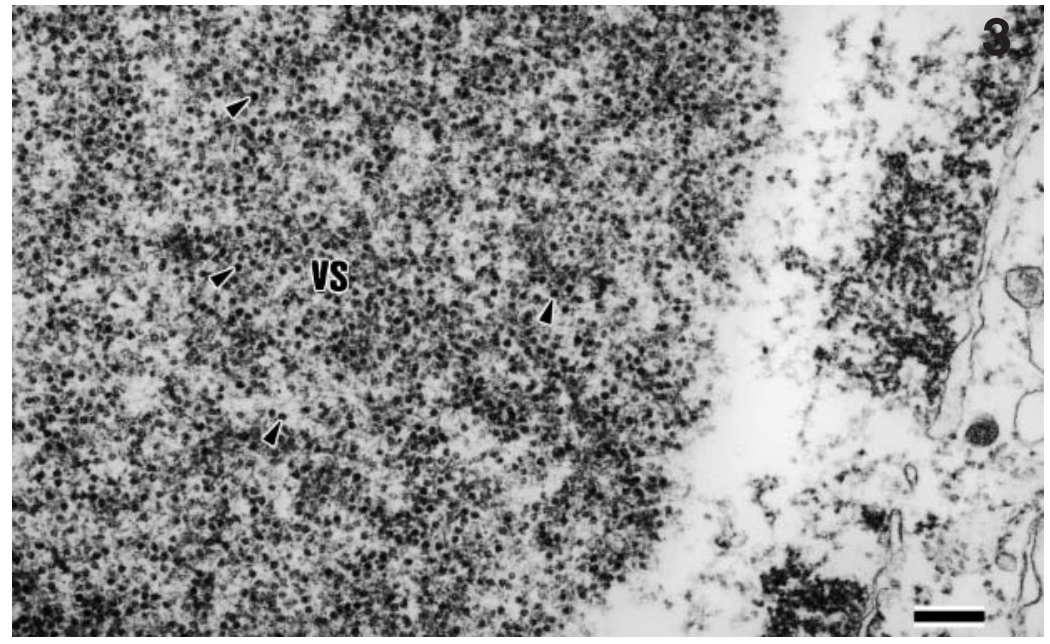

Fig. 3. Penaeus monodon. A higher magnification of HPV inclusion body in Fig. 2 within nucleus of a hepatopancreatocyte. Unenveloped, roughly spherical particles (arrowheads), 18 to $22 \mathrm{~nm}$ in diameter, are embedded in the virogenic stroma (VS). Uranyl acetate and lead citrate stain; scale bar $=200 \mathrm{~nm}$

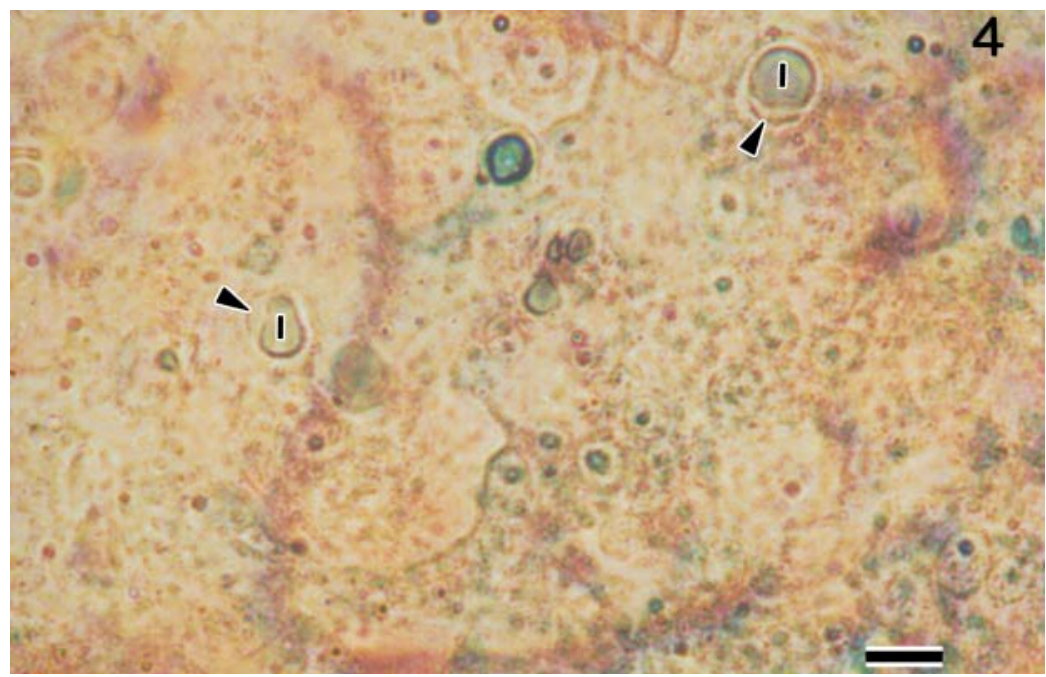

Fig. 4. Penaeus monodon. Wet mount of hepatopancreas from experimentally infected postlarvae showing large inclusion bodies (I) within epithelial cells of distal tubules that typically characterize HPV infection; displacement of nucleoli

(arrowheads) is also apparent. Malachite green stain; scale bar $=10 \mu \mathrm{m}$

Table 2. Penaeus monodon. Percentage of experimentally induced HPV infection, based on wet mounts of hepatopancreatic tissues and histopathology, in postlarvae (PL) fed virus-infected PL. (Postlarvae were at Stage PL-23 at start of experimental infection. Day p.i.: no. of days post-infection; total no. samples: total from 4 tanks infected with HPV; HPV-pos: total no. of HPV-positive samples from 4 tanks infected with HPV)

\begin{tabular}{|c|c|c|c|c|c|c|}
\hline \multirow{2}{*}{$\begin{array}{l}\text { Day } \\
\text { p.i. }\end{array}$} & \multicolumn{3}{|c|}{ Wet mount } & \multicolumn{3}{|c|}{ - Histopathology } \\
\hline & Total no. samples & HPV-pos & $\%$ & Total no. samples & HPV-pos & $5 \%$ \\
\hline 1 & 20 & 6 & (30) & 40 & 13 & $(32.5)$ \\
\hline 3 & 20 & 12 & (60) & 40 & 38 & (95) \\
\hline 5 & 20 & 19 & (95) & 39 & 38 & (97) \\
\hline 7 & 20 & 20 & $(100)$ & 40 & 40 & $(100)$ \\
\hline
\end{tabular}

The percentage of HPV infection increased dramatically to $60 \%$ by Day 3 p.i., $95 \%$ by Day 5, and had reached $100 \%$ by Day 7 . Since only half the water was replaced every $24 \mathrm{~h}$, the significant increase in HPV by Day 3 p.i. could be attributable to the dead HPV-infected PL being eaten by the remaining experimental PL. It could also be due to secondary transmission from the PL that were initially infected at $24 \mathrm{~h}$ p.i. and cannibalized by the experimental PL.

No inclusion bodies were observed in samples from the control tank (Tank 1). However, on Day 1 p.i., 1 sample from 1 tank of the experimental group (Tank 5) exhibited MBV infection manifested by the presence of multiple occlusion bodies in the hepatopancreas. On Day 3 p.i., samples from the control tank (Tank 1) also displayed MBV, along with some PL from Tanks 4 and 5. This had spread to some PL in Tanks 2 and 3 by Days 5 and 7 p.i. It is likely that the PL suffered latent MBV infection.

Histopathology was also used to confirm the preliminary data obtained from the wet-mount technique. No remarkable difference was observed in the percentage of HPV infection among the experimental PL on each sampling day, except on Day 3 p.i. (Table 2), when considerably higher HPV prevalence was detected by histopathology compared to the wet-mount technique. These results indicate that the wetmount technique can be used to screen PL for both MBV and HPV, but that a more sensitive and rapid diagnostic technique is required for HPV since low infection is difficult to detect by the wet-mount technique alone.

Histopathological examination of samples collected on Days 1 and 3 p.i. revealed an early stage of infection, as characterized by the presence of both developing and (very few) large basophilic intranuclear inclusion bodies in some of the hepatopancreatocytes, with some cells still uninfected (Fig. 5). As described in the foregoing subsection, some hepatopancreatocytes exhibited 2 inclusion bodies. At an advanced stage of infection on Days 5 and 7 p.i., almost all the epithelial cells of the distal 

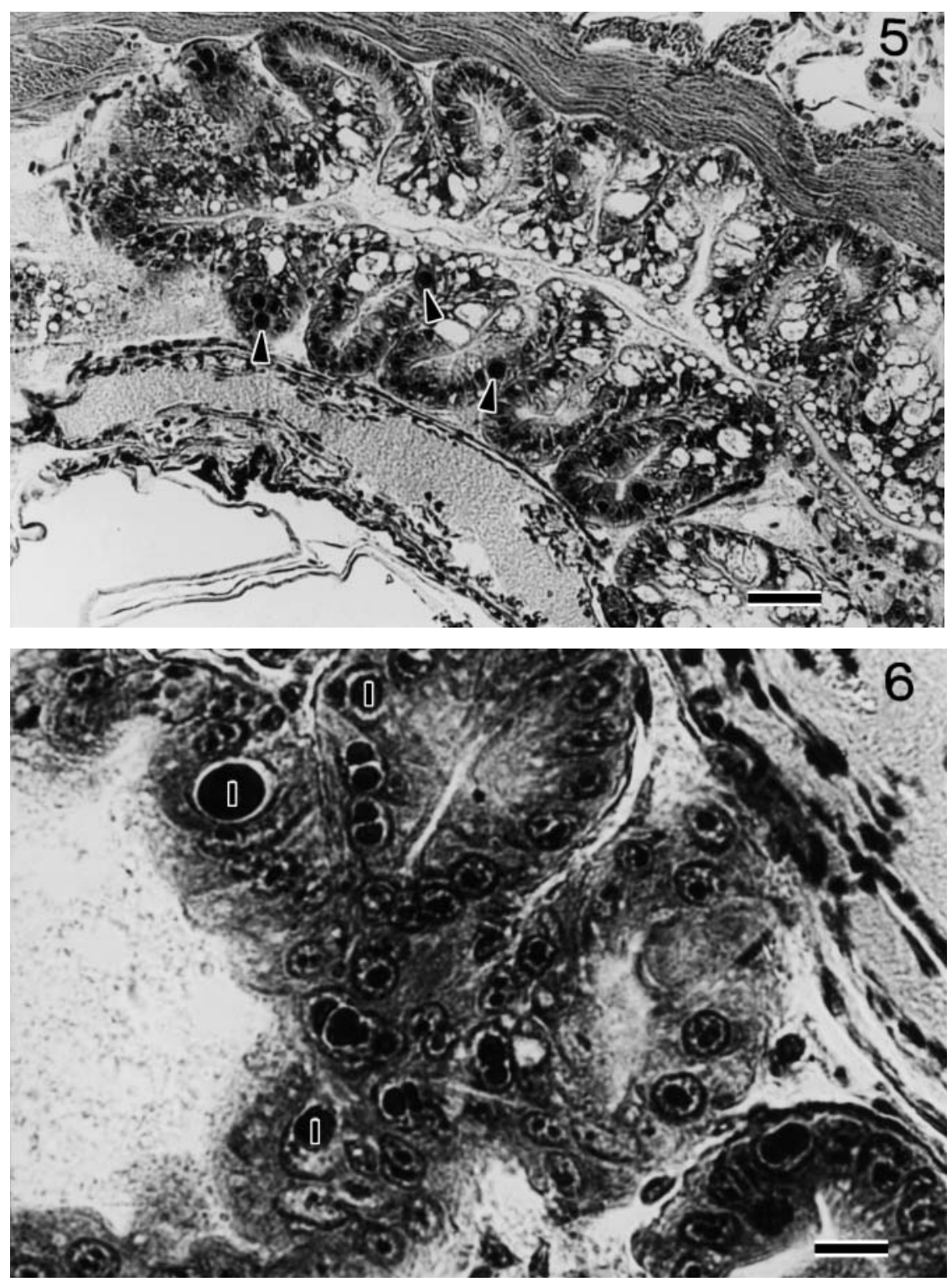

Fig. 5. Penaeus monodon. Experimentally infected postlarvae with HPV on Day 3 post-infection illustrating early stage of infection and presence of some basophilic inclusion bodies (arrowheads) within hypertrophied nuclei of some epithelial cells of distal tubules of hepatopancreas, while other cells appear normal. H\&E stain; scale bar $=40 \mu \mathrm{m}$ tubules had been infected with large, mostly single, HPV inclusion bodies (Fig. 6). No remarkable haemocytic response or necrosis was observed in the affected hepatopancreatic tissues.

The role of various factors such as MBV dual infection, shrimp growth stage, susceptibility of shrimp species and viral concentration or dose on HPV infections still needs to be clarified. Thus, further experiments are necessary to improve this infection model. Some caution is warranted in the use of the wet-mount technique to detect HPV, since this method is primarily used for MBV detection. Therefore, there is a need to validate the sensitivity and specificity of the wetmount technique as a screening method for HPV in order to avoid inaccuracy and uncertainty, especially in cases of mixed viral infections in shrimps.
Acknowledgements. The authors are grateful to Dr. Y. Inui for his comments, which improved the manuscript, for the financial assistance provided by the Government of Japan Trust Fund granted to the SEAFDEC-AQD and for Y.M. grant from JIRCAS. The first batch of postlarvae samples from the Iloilo hatchery were obtained with the help of Dr. Gilda Lio-Po.

\section{LITERATURE CITED}

Bell TA, Lightner DV (1988) A handbook of normal penaeid shrimp histology. World Aquaculture Society, Baton Rouge, LA

Fegan DF, Flegel TW, Sriurairatana S, Waiyakruttha M (1991) The occurrence, development and histopathology of monodon baculovirus in Penaeus monodon in southern Thailand. Aquaculture 96:205-217

Flegel TW, Thamavit V, Pasharawipas T, Alday-Sanz V (1999) 
Statistical correlation between severity of hepatopancreatic parvovirus infection and stunting of farmed black tiger shrimp (Penaeus monodon). Aquaculture 174: 197-206

Gomez DK (1998) Prevalence of hepatopancreatic parvo-like virus (HPV) infection in hatchery-reared Penaeus monodon postlarvae in Panay. MS thesis, University of the Philippines in Visayas

Hammer HS, Stuck KC, Overstreet RM (1998) Infectivity and pathogenicity of Baculovirus penaei (BP) in cultured larval and postlarval Pacific white shrimp, Penaeus vannamei, related to the stage of viral development. J Invertebr Pathol 72:38-43

Lightner DV (1996) A handbook of pathology and diagnostic procedures for diseases of penaeid shrimp. World Aquaculture Society, Baton Rouge, LA

Lightner DV, Redman RM (1985) A parvo-like virus disease of penaied shrimp. J Invertebr Pathol 45:47-53

Lightner DV, Bell TA, Redman RM, Mohney LL, Natividad JM, Rukyani A, Poernomo A (1992) A review of some major diseases of economic significance in penaeid prawns/shrimps of the Americas and Indopacific. In: Shariff M, Subasinghe RP, Arthur JR (eds) Diseases in Asian aquaculture. I. Fish Health Section, Asian Fisheries Society, Manila, p 57-80

Lightner DV, Redman RM, Moore DW, Park MA (1993) Development and application of a simple and rapid diagnostic method to studies on hepatopancreatic parvovirus of penaeid shrimp. Aquaculture 116:15-23

Mari J, Lightner DV, Poulos BT, Bonami JR (1995) Partial cloning of the genome of an unusual shrimp parvovirus (HPV): use of gene probes in disease diagnosis. Dis Aquat Org 22:129-134

Natividad JM, Lightner DV (1992) Susceptibility of the differ-

Editorial responsibility: Timothy Flegel,

Bangkok, Thailand ent larval and postlarval stages of black tiger prawn, Penaeus monodon Fabricius, to monodon baculovirus (MBV). In: Shariff M, Subasinghe RP, Arthur JR (eds) Diseases in Asian aquaculture. I. Fish Health Section, Asian Fisheries Society, Manila, p 111-125

Pantoja CR, Lightner DV (2000) A non-destructive method based on the polymerase chain reaction for detection of hepatopancreatic parvovirus (HPV) of penaeid shrimp. Dis Aquat Org 39:177-182

Phromjai J, Sukhumsirichart W, Pantoja C, Lightner DV, Flegel TW (2001) Different reactions obtained using the same DNA detection reagents for Thai and Korean hepatopancreatic parvovirus of penaeid shrimp. Dis Aquat Org 46:153-158

Platon RR (1999) Shrimp aquaculture: the Philippine experience. ACIAR Proc 90:63-68

Roubal FR, Paynter JL, Lester RJG (1989) Electron microscopic observation of hepatopancreatic parvo-like virus (HPV) in the penaeid prawn, Penaeus merguiensis de Man, from Australia. J Fish Dis 12:199-201

Soto MA, Shervette VR, Lotz JM (2001) Transmission of white spot syndrome virus (WSSV) to Litopenaeus vannamei from infected cephalothorax, abdomen, or whole shrimp cadaver. Dis Aquat Org 45:81-87

Spann KM, Adlard RD, Hudson DA, Pyecroft SB, Jones TC, Voigt MOC (1997) Hepatopancreatic parvo-like virus (HPV) of Penaeus japonicus cultured in Australia. Dis Aquat Org 31:239-241

Sukhumsirichart W, Wongteerasupaya C, Boonsaeng V, Panyim S, Sriurairatana S, Withyachumnarnkul B, Flegel TW (1999) Characterization and PCR detection of hepatopancreatic parvovirus (HPV) from Penaeus monodon in Thailand. Dis Aquat Org 38:1-10

Submitted: January 28, 2003; Accepted: July 9, 2003

Proofs received from author(s): October 9, 2003 